\title{
A EVOLUÇÃO DO COMÉRCIO JUSTO E SUA APLICAÇÃO COMO DIREITO TRANSNACIONAL
}

\author{
Joana Stelzer ${ }^{1}$ \\ Alexandre Pinto Moreira ${ }^{2}$
}

\section{RESUMO}

$\mathrm{O}$ artigo avaliou o comércio justo e a possibilidade de regulamentação por intermédio de normas transnacionais. Nesse sentido, foi necessária incursão acerca do desenvolvimento do capitalismo até chegar ao neoliberalismo decorrente da globalização econômica. Confirmouse a possibilidade de regulação do comércio justo por normas transnacionais, como conceito adequado para a contemporaneidade e forma de aplicação de direitos de solidariedade, de caráter mundial (e não por Estados nacionais). Trata-se de investigação qualitativa, servindose primordialmente do meio bibliográfico. O método de abordagem utilizado é o hipotético dedutivo e, quanto aos fins, trata-se de análise descritiva.

Palavras-chave: Globalização Econômica; Normas Transnacionais; Comércio Justo; Direitos de Solidariedade.

\section{THE EVOLUTION OF FAIR TRADE AND ITS APPLICATION AS A TRANSNATIONAL LAW}

\begin{abstract}
The article assessed Fair Trade and the possibility of regulation through transnational standards. In this sense an incursion into the development of capitalism was necessary until neoliberalism emerged as a result of economic globalization. The possibility of regulating fair trade by transnational rules was confirmed as an adequate concept for contemporaneity and form of application of rights of solidarity world-wide (and not by national states). This study is a qualitative research, using bibliographic means. The method of approach used is the hypothetical deductive and for purposes it is a descriptive analysis.
\end{abstract}

Key-words: Economic Globalization; Transnational Standards; Fair Trade; Rights of Solidarity.

\section{Introdução}

O capitalismo evoluiu como sistema econômico até atingir seu ápice após a Segunda Guerra Mundial com os acordos de Bretton Woods que propiciaram o início de relações comerciais globais - nas quais os países hegemônicos poderiam comercializar seus produtos no âmbito de qualquer Estado com o mínimo de restrições. Nessa ocasião e sob tal contexto, articularam o General Agreement on Tariffs and Trade (GATT). A globalização, por sua vez,

\footnotetext{
${ }^{1}$ Doutora e Mestre em Direito (UFSC). Professora credenciada no Programa de Pós-Graduação em Direito (PPGD/UFSC)

${ }^{2}$ Professor das Faculdades de Direito da UVA (Vale do Acaraú) e Faculdade Luciano Feijão. Professor da Escola Superior do MP/CE. Especialista Processo Judicial (UVA-CE). Mestrando em Direito da PPGD/UFSC.
} 
deu origem ao neoliberalismo e às suas regras ditadas pelo Consenso de Washington que visavam a um crescimento econômico, embora aumentassem a desigualdade de renda. Sob tal escopo, determinou o surgimento de um cenário transnacional, no qual as relações comerciais seriam reguladas por normas de comércio internacional desvinculadas do Estado (Nacional), em nítido processo de mitigação soberana.

Surge então uma percepção que a desigualdade entre os países do Sul e do Norte se tornava cada vez mais intensa. Em algumas regiões da Europa e dos Estados Unidos manifestava-se um movimento denominado Fair Trade (Comércio Justo), cujo intuito era estimular a aquisição de produtos do Sul por países desenvolvidos, desde que resultassem de critérios éticos e sustentáveis. Tratava-se, inclusive, de um contraponto ao consumismo acrítico. Sob a ótica europeia e americana, o denominado Fair Trade vicejava enquanto política de assistência indireta (na tentativa de minimizar políticas de transferência de renda estatal). Na América Latina e no Caribe, entretanto, o Comércio Justo ganharia outra conformação. Ainda marcada pelas experiências do mundo indígena, campesino e tradicional, os processos econômicos e comerciais alternativos trouxeram uma "outra realidade". Sob tal proposta, não se tratava de assistencialismo, mas, de articulação de valores distintos do capitalismo, como resultado de uma experiência a partir das bases.

Em que pesem as diferenças nos movimentos, o Comércio Justo será uma manifestação de direitos fundamentais de terceira geração, referindo-se a direitos de solidariedade, que visam ao desenvolvimento por intermédio da produção, comercialização e consumo, de forma ética e sustentável. A implantação normativa e fenomenológica não ocorre pelas vias tradicionais do Estado-nação, mas, por intermédio de normas transnacionais reflexivas da globalização econômicas.

Sob tal contextualização, emerge o seguinte problema investigatório: as normas de Comércio Justo assumem a natureza jurídica de ordenamento com natureza transnacional, influenciado pela globalização? Com efeito, a falta de representatividade popular em esfera internacional, tem feito que a sociedade procure alternativas ao diálogo pautado na exclusividade do Estado enquanto interlocutor externo. Princípios e procedimentos de Comércio Justo são capitaneados por Organizações Não Governamentais à margem do sistema westfaliano.

Com base nessas informações, tem-se como objetivo geral desta pesquisa diagnosticar o Comércio Justo conforme um cenário de normas transnacionais. Tendo por 
temática central o comércio internacional os seguintes objetivos específicos também foram perseguidos: traçar um cenário da evolução do capitalismo até a Segunda Guerra mundial; evidenciar como surgiu a globalização econômica e sua manifestação por intermédio do neoliberalismo; e, constatar a existência de normas transnacionais, com possibilidade de compatibilização relativamente ao Comércio Justo como manifestação de direitos de solidariedade.

Justifica-se o estudo, pois se entende que as normas comerciais devem ter a solidariedade humana como meta inarredável, mesmo quando se está discutindo o comércio mundial. Entre as pesquisas que se apresentaram para explicar a evolução do contexto externo que balizaram as regras comerciais tradicionais, destacam-se Fernand Braudel e Jeffry Frieden. No âmbito das discussões sobre a natureza jurídica das emergentes regras transnacionais sobressaem José Eduardo Faria, Ulrich Beck, Octavio Ianni e Joana Stelzer. Quanto ao comércio internacional, nas propostas de comércio tradicional (free trade) e Comércio Justo foram utilizados autores como Marco Coscione, Rosemary Gomes e Alfonso Cotera Fretel; além do site institucional da Coordenadora Latino-americana e do Caribe de Pequenos Produtores e Trabalhadores do Comércio Justo.

O método de abordagem foi o crítico hipotético-dedutivo, por se perceber que o ordenamento relativo ao comércio internacional é inadequado para a contemporaneidade e que se deseja propor novo referencial, segundo uma proposta transnacional de Comércio Justo. Os dados e as informações foram examinados sob forma qualitativa. Os meios de pesquisa foram exclusivamente bibliográficos, coletados por duas fontes secundárias de informação: prioritariamente, a partir de produção científica, à luz de reconhecidas obras doutrinárias; e, também, sites institucionais relativos ao assunto. Quanto aos fins, a pesquisa apresenta-se de cunho descritivo. Os resultados foram expostos exclusivamente em forma de textos.

\section{0 capitalismo e a gênese das relações comerciais contemporâneas}

Historicamente, as transações comerciais ocorriam de forma direta entre os produtores que levavam os excedentes para comercializar em feiras públicas. Os consumidores, por sua vez, procuravam aqueles espaços com o intuito de adquirir os bens que necessitavam, principalmente alimentos resultantes de produções agropecuárias. Uma situação que deve ser ressaltada é descrita por Aristóteles e seu entendimento do que era justiça, tanto que um 
exemplo que era dado pelo filósofo grego utilizava uma negociação entre pessoas como forma de determinar o que poderia ser considerado justo:

Temos, pois, definido o justo e o injusto. Após distingui-los assim um do outro, é evidente que a ação justa é intermediária entre o agir injustamente e o ser vítima de injustiça; pois um deles é ter demais e o outro é ter demasiado pouco. A justiça é uma espécie de meio-termo, porém não no mesmo sentido que as outras virtudes, e sim porque se relaciona com uma quantia ou quantidade intermediária, enquanto a injustiça se relaciona com os extremos. E justiça é aquilo em virtude do qual se diz que o homem justo pratica, por escolha própria, o que é justo, e que distribui, seja entre si mesmo e um outro, seja entre dois outros, não de maneira a dar mais do que convém a si mesmo e menos ao seu próximo (e inversamente no relativo ao que não convém), mas de maneira a dar o que é igual de acordo com a proporção; e da mesma forma quando se trata de distribuir entre duas outras pessoas. (ARISTÓTELES, 1991, p.109).

Essa situação que se determinava como comércio justo na Grécia Antiga poderia acontecer mesmo que não se tratasse de uma troca, mas também se fosse utilizada uma moeda, que poderia ser assemelhado ao dinheiro. Nesses casos, conseguir-se-ia atribuir um determinado valor sem que houvesse uma pessoa se beneficiando em detrimento de outra.

\footnotetext{
Deste modo, agindo o dinheiro como uma medida, torna ele os bens comensuráveis e os equipara entre si; pois nem haveria associação se não houvesse troca, nem troca se não houvesse igualdade, nem igualdade se não houvesse comensurabilidade. Ora, na realidade é impossível que coisas tão diferentes entre si se tornem comensuráveis, mas com referência à procura podem tornar-se tais em grau suficiente. Deve haver, pois, uma unidade, unidade estabelecida por comum acordo (por isso se chama ela dinheiro); pois é ela que torna todas as coisas comensuráveis, já que todas são medidas pelo dinheiro. (ARISTÓTELES, 1991, p.108).
}

Durante significativo período na história humana, as transações comerciais se caracterizaram pelo equilíbrio de negociação entre as partes, na qual ambas negociavam diretamente e saíam satisfeitas com o negócio avençado. O início da formação dos centros urbanos com o incremento dos seus habitantes caracterizou-se como um motivo importante para a mudança na estrutura econômica, com destaque para os trabalhadores subordinados que deixaram de ter ligação com o labor rural. Essa coletividade passou a formar um novo grupo que nem era mão de obra escrava e nem agricultores, mas, que vivia nas cidades sem dispor de empregos e por conta disso não tinham meios para consumir quaisquer gêneros, sejam oriundos do campo ou das indústrias artesanais da época. Esses indivíduos passariam a compor o proletariado. O proletário distingue-se do trabalhador, pois esse pode vender seus produtos ou seus serviços, enquanto o proletário só vende sua aptidão para trabalhar. Dessa 
forma, os produtos do trabalho proletário (ou seu próprio trabalho) não pertencem à pessoa, pois está nas mãos daquele que compra essa energia e lhe paga um salário.

Mas, para que houvesse a transformação definitiva do modelo econômico vigente na época - do feudalismo para o capitalismo - era necessário algo mais até então utilizado. Era necessário que a produtividade fosse impulsionada por novas formas de produção combinadas com a realocação da mão de obra, ou seja, que os trabalhadores agrícolas migrassem para os centros urbanos industriais, assumindo novas relações de trabalho. Determinava-se, dessa forma, o surgimento do proletariado e dos detentores do capital. Tal mudança pode ser definida como a origem do capitalismo, pois coincide com o início da economia de mercado, momento em que as relações comerciais se tornaram mais intensas e que não se restringiam a negócios individuais entre os produtores e os consumidores dos produtos.

O que se observa no início dessa economia de mercado é a figura dos atravessadores que começam a agir como intermediários nas relações comerciais e impor aos produtores e consumidores a força que detém em virtude de possuírem grandes valores.

É evidente que se trata de trocas desiguais em que a concorrência - lei essencial da chamada economia de mercado - dificilmente tem lugar e onde o comerciante dispõe de duas vantagens: ele rompeu as relações diretas entre o produtor e aquele a quem a mercadoria se destina finalmente (só ele conhece as condições do mercado nas duas pontas da cadeia e, portanto, a margem de lucro que obterá), e dispõe de dinheiro para compras à vista, o que constitui seu principal argumento. (BRAUDEL, 1987, p. 26)

Tal situação vai demonstrar que a civilização que se baseava em uma economia de troca entre produtor e consumidor como forma de suprir as necessidades de cada um e que não admitia o acúmulo de bens como um objetivo de vida acaba por ser substituída por um espírito capitalista que privilegiava a aquisição de riquezas.

O espírito capitalista, surgido na Baixa Idade Média europeia, veio quebrar essa
longa tradição histórica. De um lado, passou-se a admitir como eticamente não
condenável a busca de riqueza material como finalidade última da vida. De outro
lado, firmou-se na nova classe burguesa a convicção de que o acúmulo pessoal de
bens é um poderoso instrumento de poder na sociedade. (COMPARATO, 2014, p.
54)

A burguesia passou a implementar novas técnicas de produção, pois o que se observava era o crescimento da população que deveria usufruir dessas mercadorias, ou seja, havia a necessidade de uma produção em larga escala. Tal situação fez com que a burguesia cada vez mais se consolidasse como classe dominante na seara financeira, visto que ela era 
quem regia o comércio e era detentora do capital obtido nos proveitos das transações comerciais. Por outro lado, na seara social as cidades se destacavam, pois eram tidas como entrepostos comerciais, nos quais as indústrias se fixavam e centralizavam as atividades intelectuais.

Eis o início de uma transformação mundial que teve um marco importante no século XVIII com a Revolução Industrial, na Inglaterra, desencadeada por conta de três fatores diversos. Primeiro, a expansão do comércio, que determinou uma necessidade de uma produção industrial maior. Segundo, decorrente de uma reforma agrária, nas quais as terras passaram a ser concentradas nas mãos de poucos detentores que transformaram a agricultura de um modo de vida tradicional em uma profissão lucrativa. Finalmente, o desenvolvimento tecnológico foi o fator determinante para a ocorrência da Revolução Industrial, alterando os rumos da vida humana em sociedade.

\begin{abstract}
Já foi salientado mais acima que a Revolução Industrial do século XVIII representou, após a Revolução Agrícola ocorrida entre o oitavo e o quinto milênios antes da era atual, a segunda maior transformação global da vida humana em sociedade, no curso da História. A Revolução Agrícola deu origem às sociedades agrárias, nas quais o poder era fundado na posse da terra. Eram, todas elas, sociedades autocentradas e separadas umas das outras, formando um verdadeiro arquipélago mundial, em que cada ilha enxergava nas demais um território inimigo. Já a Revolução Industrial, amplamente aproveitada pelo sistema capitalista como forma de expandir-se ilimitadamente, engendrou um mundo sempre mais unificado, em que os povos tendem, incoercivelmente, a se aproximar uns dos outros. (COMPARATO, 2014, p. 201)
\end{abstract}

Com a instituição do maquinismo, a produção em massa de uma vez por todas tomou a frente do antigo modelo de produção, na qual o produto se vinculava à terra.Com o advento das grandes fábricas e da larga escala de produção, a mercancia também sofreu alterações, pois na medida em que cada cidade se especializava na produção de determinado produto, avolumava também a necessidade do intermitente comércio entre locais diferentes.

O Mundo então se transformava drasticamente, os fatores de produção eram outros e a tendência era a produção em larga escala. Os países europeus como os primeiros a se industrializar eram detentores de grande parte da produção industrial dos artefatos que à época começavam a se tornar indispensáveis ao homem, objetos esses que por conta de suas características possuíam um grande valor.

Diante desse contexto as formas de trabalho também viriam a sofrer alterações, a mão de obra que até então era inteiramente voltada para produção rural teve que se adaptar ao novo modelo econômico e às novas formas de laborar. Percebia-se uma mutação social como 
consequência do processo de urbanização das cidades que, vinculadas à industrialização, fez com que surgisse o proletariado. Em decorr ência da utilização das máquinas, entendida como mais eficiente sob a ótica econômica, lentamente ocorria também a substituição do trabalho humano. Longas jornadas de trabalho sob condições precárias e remuneração irrisória desenharam o retrato da época. Tal relação com os empregados viabilizou a criação de relações impessoais e o advento da sociedade de massa.

A presença do homem na linha de produção foi se tornando prescindível, fazendo com que o capitalismo industrial deflagrasse mudanças na essência da sociedade clássica. Anteriormente formada por várias comunidades e interação moderada, a sociedade tinha como característica relações sociais de caráter mais humanista.

O sistema de capitalismo decorrente da Revolução Industrial ocasionou o aparecimento de uma sociedade na qual as pessoas além de não possuir distinção acabavam por desprezar umas às outras, ocasionando uma uniformização do modo de pensar que redundou no fim de individualidades nas peculiaridades sociais. Costumes seculares foram sendo deixados para trás, pois o que determinava o pensamento e as atitudes era o capitalismo industrial, cuja produção demandava a expansão de um consumo desenfreado. Lentamente, assistiu-se à mitigação das tradições e novas tendências de caráter mundial ganharam forma, a exemplo do consumo acrítico do mundo da moda, evidenciando também a homogeneização de comportamento.

Após a Revolução Industrial a economia de mercado começou a se tornar mais presente e se percebeu sua proliferação em escala global, iniciando um período de fortificação do capitalismo que só seria abalado com a Grande Depressão em decorrência do crash da Bolsa de Nova York em 1929. O período ulterior foi marcado por uma tentativa frustrada de recuperação até que a Segunda Guerra Mundial desencadeasse seus horrores.

\section{Globalização econômica, neoliberalismo e transnacionalidade: diretrizes do direito do comércio internacional}

Com o término da Segunda Guerra Mundial (e já durante ela), percebeu-se a ascensão dos Estados Unidos frente às outras economias mundiais, principalmente as europeias que enfrentavam graves dificuldades em decorrência dos gastos com o conflito armado. A hegemonia norte-americana determinou que se realizasse uma conferência para deliberar um formato para a economia do pós-guerra. 
Em 1947, a partir dos Acordos de Bretton Woods (e já antes com a Carta do Atlântico, em 1941) instigou-se fortemente o processo de abertura das economias nacionais para o comércio internacional, tendo os Estados Unidos como grande beneficiário. Para expandir seus negócios, os estadunidenses precisavam de abertura das economias estrangeiras e para isso demandavam uma diminuição drástica nas tarifas de comércio. Com isso, também geraram uma possibilidade de ingresso de suas empresas multinacionais em territórios estrangeiros, organizações essas que aumentaram bastante seus lucros sem transferência de tecnologia ao país hospedeiro. Esse já era um efeito da globalização, especialmente em virtude da desterritorialização de produção que procurava nos baixos salários e abundância de matéria-prima os fatores que motivavam a saída das empresas dos EUA.

Com o cenário econômico delineado, restava aguardar o fim da Segunda Guerra Mundial e a aceleração da globalização. A velocidade das trocas de informações e meios de transporte cada vez mais rápidos tornou fácil a superação das distâncias geográficas. Apontar o início do processo global é tema controvertido. Enquanto alguns defendem que seu desencadeamento possui características inerentes do tecnicismo, próprias do pós-guerra, há renomados estudiosos que preferem defender o início em tempo remoto, a exemplo de José Eduardo Faria:

\begin{abstract}
Globalização também não é um fenômeno novo. Ele já estava presente, por exemplo, nos antigos impérios, provocando sucessivos surtos de modernização econômica, cultural e jurídica. Na era moderna, foi impulsionado pela interação entre a expansão da cartografia, o crescente domínio das técnicas de navegação pelos povos ibéricos e a própria evolução do conhecimento científico. Esses foram os fatores responsáveis pelas grandes descobertas e pelos projetos ultramarinos de Portugal e Espanha, a partir do final do século XV; pelas novas formas manufatureiras desenvolvidas em Florença, Gênova, Milão, Veneza e outras cidades do norte da Itália, no século XVI; e pela formação de um sistema internacional de pagamentos baseado em letras de câmbio entre banqueiros e negociantes, tomando possível o estabelecimento de rotas globais de comércio, a exploração sistemática do ouro e da prata nas Américas, o início de um amplo e complexo processo de colonização e expansão territorial, a chegada da civilização europeia aos extremos da Ásia e a formação de estruturas decisórias (....). (FARIA, 1999, p. 60)
\end{abstract}

Em que pesem as divergências doutrinárias, a presente investigação interessa-se no processo deflagrado a partir de Bretton Woods e que começou a ter reflexos nas economias de vários países, principalmente aumentando a desigualdade entre os países dos hemisférios Norte, mais rico; e, Sul, cada vez mais pobre.

A expansão dos meios de transporte fez surgir a necessidade cada vez maior da produção de petróleo, além da indústria que a utilizava como matéria prima. Tal necessidade 
fez com que surgissem as crises do petróleo que ocorreram em 1973 e 1979, momento no qual os países produtores elevaram bastante os valores do combustível fóssil e causaram uma acentuada queda do crescimento econômico de vários países. Além do mais, os países produtores tiveram um aumento expressivo em suas reservas monetárias e com o intuito de não deixar esses valores ociosos, e em comum acordo com grupos bancários internacionais, iniciaram uma grande oferta de crédito tanto para Estados (na maior parte dos casos de países subdesenvolvidos) quanto para entes particulares.

A oferta de crédito acabou gerando endividamento e consequentemente fez surgir um novo modelo geral de organização da atividade econômica que redundou na criação do neoliberalismo. O neoliberalismo foi implantado sob a batuta de John Williamson após o Consenso de Washington, tendo a importante contribuição das políticas econômicas de dois grandes países: a Inglaterra, sob o auspício de Margareth Thatcher; e, os Estados Unidos, sob a presidência de Ronald Reagan.

O que se viu foi a expansão do neoliberalismo como fórmula ao desenvolvimento de várias economias pelo mundo, receita a qual poucos tinham coragem de retorquir.

\begin{abstract}
O novo ponto de vista, cujo nome variava - livre mercado, neoliberalismo ou ortodoxia -, adotava a austeridade anti-inflacionária, cortes de impostos e gastos, privatização e desregulamentação. O "Consenso de Washington", como foi rotulado pelo economista John Williamson, logo se tornou o princípio para a organização da maioria das discussões sobre política econômica. O Consenso de Washington repercutia com força crescente no mundo em desenvolvimento, durante a luta dos países contra as crises da dívida e de crescimento dos anos 1980 e também no mundo comunista, que se afastava do planejamento central dos anos 1990. No fim do século, havia mais concordância em torno da doutrina econômica do que em qualquer outra época desde 1914. Alternativas à ortodoxia, fossem elas comunistas, radicais, desenvolvimentistas ou populistas eram fracas ou inexistentes. Era difícil encontrar partidários do planejamento, da substituição de importações ou da ampla propriedade estatal em qualquer lugar do planeta. Havia divergências "dentro de casa" entre os pensadores voltados para o mercado, mas poucos colocavam em dúvida a superioridade geral dos mercados como mecanismos de alocação econômica.(FRIEDEN, 2008, p.239)
\end{abstract}

Essas medidas passaram a servir de manual para ser seguido por qualquer Estado que desejasse que sua economia se estabilizasse e não importava quais fossem as consequências, mesmo que se oprimissem os mais pobres e se beneficiassem os mais ricos, mesmo assim deveriam ser aplicadas.

\title{
3 A Transnacionalização sob o enfoque econômico e jurídico
}


O cenário de globalização descrito determinou o enfraquecimento dos modelos estatais existentes. A força do mercado passou a ditar regras que alterariam a engenharia jurídica do Estado. Ideias e interesses capitalistas fariam sucumbir modelos desgastados e a produção normativa não ficaria isenta desses efeitos. De plano, percebia-se a força do mercado que fazia com que ordenamentos jurídicos perdessem a importância quando não fornecessem respostas convincentes em apoio ao mercado.

O direito interno deixaria de ser utilizado enquanto via para a solução de conflitos sempre que não resultasse (ou não fosse o efeito) de relações comerciais ou econômicas globalizadas. Se, em um determinado momento da história o indivíduo tinha o direito para se proteger do Estado, isso deixou de acontecer quando a inexistência de normas acabava por não protegê-lo do mercado. Essa força fez com que se criasse uma sociedade global que traria uma nova face para a história da humanidade.

\footnotetext{
Aqui recomeça a história. Em lugar das sociedades nacionais, a sociedade global. Em lugar do mundo dividido em capitalismo e socialismo, um mundo capitalista, multipolarizado, impregnado de experimentos socialistas. Uma sociedade global no sentido de que compreende relações, processos e estruturas sociais, econômicas, políticas e culturais, ainda que operando de modo desigual e contraditório. (IANNI, 2014, p. 36, 39)
}

Esse processo permitiu o crescimento acelerado da zona de influência de empresas transnacionais que conseguiam fracionar a sua área produtiva de uma forma que pudesse se instalar em países diferentes de acordo com as suas conveniências comerciais. Assim, passaram a dividir sua linha de produção muitas vezes em continentes diferentes, buscando vantagens de produção: benefícios fiscais, melhores cenários monetários, legislações trabalhistas mais flexíveis, organizações sindicais menos mobilizadas, entre outros. Tudo isso com o intuito de diminuir seus custos e auferir maior lucro possível.

Basta que existisse certa permeabilidade em um determinado país que a distância geográfica não representaria um empecilho e principalmente porque muitos dos processos que regulavam essas relações comerciais não ficavam adstritos a nenhuma legislação de nenhum Estado nacional. Diversos assuntos jurídicos passavam a ser administrados por entidades privadas que regulavam o comércio internacional. Consolidava-se a ideia de sociedade global, perceptível por intermédio de fatores como a intensificação nas relações comerciais. 
foi motivado por demandas do sistema comercial mundial que precisavam da diminuição de custos para amalgamar o intenso fluxo de bens. Não por coincidência, os períodos nos quais a globalização é avaliada como mais intensa, é também o período no qual as trocas comerciais são mais significativas. (STELZER, 2009, p. 23)

A emergente sociedade global começava a ter trocas comerciais que não se submetiam mais ao crivo e às leis de Estados exclusivamente, até porque passava a haver transações entre Corporações Internacionais (CTNs) que já possuíam tentáculos em diversos países, seja produzindo, seja estimulando o consumo por parte da população. Percebia-se o surgimento de normas que não eram vinculadas a nenhum Estado (nacional) e tampouco eram normas objeto de tratados entre nações (internacionais). Tratava-se, sim, de normas editadas por grupos privados (transnacionais) e que passaram a servir de parâmetro para as relações comerciais no globo terrestre.

Tais normas fugiam do âmbito do direito internacional e passavam para o que se chama de norma transnacional, em verdadeiro processo de transcendência do conceito tradicional de norma decorrente da soberania estatal, pois iam além do Estado, percebendo-se a sua permeabilidade. Para Faria (1999, p. 62 e ss.), a transnacionalidade é um fenômeno reflexivo da globalização e sob tal escopo explica Stelzer:

\footnotetext{
Fenômeno reflexivo porque a transnacionalidade caracteriza-se pela permeabilidade estatal e criação de uma terceira dimensão social, política e jurídica, que perpassa a realidade nacional, mas que não se confunde com ligação ponto-a-ponto da internacionalidade. Assim, enquanto a globalização é o fenômeno envolvedor, a transnacionalidade é a nascente de um terceiro espaço, inconfundível com o espaço nacional ou internacional. (STELZER, 2009, p. 21)
}

Tal explicação é importante para fundamentar o entendimento de Cruz (2009) que após considerações sobre a etimologia do prefixo trans e sobre o conceito jurídico de Nação, assim sintetiza o conceito de transnacional:

Daí que se pode, juntando o prefixo trans e o conceito de Nação e caracterização de Nação Jurídica, entender por Transnacional os novos espaços públicos não vinculados a um território específico, que perpassam a ideia tradicional de Nação Jurídica, aceitam a pluralidade como premissa e possibilitam o exercício de poder a partir de uma pauta axiológica de comum consensual, destinada a viabilizar a proposição de um novo pacto de civilização.(CRUZ, 2009, p. 61)

Assim, após a identificação dessas transações transnacionais é importante que as mesmas sejam contextualizadas dentro de um universo jurídico. Afinal, quando se insere no contexto do direito há certa dificuldade em se definir o que poderia exemplificar, ou mesmo 
confirmar, a existência de um direito transnacional, principalmente por não se vislumbrar uma norma decorrente da soberania estatal interna ou decorrente de acordos externos entre Estados diferentes. Nesse ponto do estudo, há um retorno ao cenário das relações comerciais que se regem por normas não vinculadas a Estados.

Fala-se em uma nova lex mercatoria que, em aplicação similar àquela existente no medievo, possui uma manifestação autônoma de práticas, regras e mesmo princípios que são criados e implantados por uma comunidade de empresas transnacionais cujo objetivo é propiciar uma autorregulação das relações comerciais. Há ainda a necessidade de se regular a produção transnacional, a fim de que se produzam mercadorias que atendam ao mercado em um nível global e não somente no âmbito de um país. Daí a necessidade de se compendiar normas que possam uniformizar técnicas que devem atender quaisquer determinações de padrões mínimos tanto de qualidade como de segurança dos bens e serviços que se propõem a ser produzidos ou oferecidos em âmbito transnacional.

No que tange às relações comerciais é importante que se contextualize e se tome como exemplo a Câmara de Comércio Internacional - CCI (International Chamber of Commerce - ICC), sediada em Paris. A CCI foi fundada em 1919 com um objetivo global que permanece inalterado: servir ao mundo empresarial através da promoção comercial e de investimento, e abrir os mercados de bens, serviços e livre fluxo de capitais. Esta organização internacional criou o Tribunal Internacional de Arbitragem, em 1923, a quem as Corporações Internacionais recorrem para resolução de conflitos decorrentes das transações comerciais.

De forma mais específica quanto à prática das transações comerciais há os Incoterms, que em português significa Termos internacionais de comércio que foram criados pela CCI em 1936.

\begin{abstract}
Os Incoterms representam norma transnacional, a atualização mais recente está em vigor desde 01.01.2000, denominada Publicação 560 da CCI e também conhecida por Incoterms 2000. Uma vez agregados aos contratos de comércio, os termos passam a ter força legal, assegurando a execução judicial, caso necessário. Apesar de ausente regra nacional que incorpore tal Direito, os termos incorporaram-se ao uso jurídico cotidiano nos negócios mundiais. A diversidade nas formas de comerciar restou motivando linguagem que transpassasse as fronteiras, em sintonia com as necessidades do cotidiano global. (STELZER, 2009, p. 42)
\end{abstract}

Outra manifestação da referida transnormatividade são os títulos de crédito para negociações internacionais, conhecidas como norma UCP (Customs ans Practice for Documentary Credits). Tratam-se de normas que regulamentam o uso das Cartas de Crédito 
em negócios mundiais, e pode ser considerado um instrumento de pagamento bancário utilizado com maior importância. A aceitação da UCP retrata características de um ordenamento transnacional.

\begin{abstract}
A aceitação dessas normas por toda a comunidade bancária para disciplinar o Crédito Documentário no âmbito do comércio mundial retrata quatro marcantes características de um ordenamento transnacional: a) necessidade de ordenamento capaz de harmonizar e trazer procedimentos de forma singular para os envolvidos, percebendo-se um vazio jurídico que deveria ser coberto pelos Estados; b) consequente criação de norma à margem do Estado (nesse caso, resultante dos trabalhos da CCI; c) inexistência de recepção normativa formal por parte dos Estados, porque não se trata de tratado internacional; seja porque serve aos interesses dos bancos em transações de comércio mundial, de modo que é indiferente a recepção; d) cogência das cartas de crédito documentário, que podem ser executadas na esfera do poder judiciário, embora a arbitragem privada seja o espaço jurídico transnacional predominante na solução de disputas. (STELZER, 2009, p. 40)
\end{abstract}

Em complemento às normas UCP surgiram as disposições da International Standard Banking Practices (ISBP) que visam à interpretação uniforme dessas regras, indicando aos bancos as obrigações as quais devem se vincular.

Outra forma de representação de norma transnacional decorre da arbitragem comercial. Nessa situação, constata-se que ao se eleger um determinado órgão arbitral para solução de litígios entre as partes de uma transação comercial, essas normas não se limitam a um determinado território soberano e não se submetem a regras de ordem pública. O que se constata é que nessas referidas transações o campo de interesse diz respeito à existência de uma técnica para solucionar lides privadas. Com efeito, faz sentido a presença de julgadores com conhecimentos específicos nos temas a serem dirimidos, pois são causas com abordagem precisa, ritos procedimentais céleres e sem preocupações de caráter social, pois não haveria nenhuma influência do Poder Público.

Essa adoção da arbitragem determinou que em 1985, fossem unificados os procedimentos arbitrais com a criação da United Nations Comission for Internacional Trade Law (Comissão das Nações Unidas para a Legislação Comercial Internacional) - a Uncitral, cujas regras de arbitragem servem de referência para os comerciantes, embora não se configure como o espaço arbitral para solução de litígios.

Tem-se como principais foros de arbitragem mundial a Corte Internacional de Arbitragem, alocada na Câmara de Comércio Internacional (CCI); a American Arbitration Association (AAA); e, a London Court of Arbitration. É importante ressaltar também a 
existência de cortes arbitrais importantes que tratam de assuntos econômicos específicos como The Refined Sugar Association (RSA), The Grain and Feed Trade Association (GAFTA), The London Metal Exchange (LME), The Green Coffee Association e a London Maritime Arbitration Association.

A transnacionalização é uma emergente realidade sob o aspecto econômico que necessita de juridicidade. Não se trata de um liberalismo sem regras, mas um conjunto normativo hábil para orientar e dirimir os negócios além fronteiras, sejam elas fruto do comércio tradicional (free trade) ou do comércio justo.

\section{O Comércio Justo como aplicação de direitos fundamentais sob uma perspectiva transnacional}

Fica evidente que a transnacionalização enquanto forma de regular transações comerciais é bem presente e serve de instrumento ao capitalismo e à economia globalizada, aumentando o fosso existente entre países desenvolvidos do hemisfério norte e subdesenvolvidos do hemisfério sul. No entanto, é importante que se aprofunde o estudo para saber se há normas transnacionais com o intuito de fortalecer a garantia de direitos fundamentais, constantemente violados pela ausência de garantias de cumprimento dos Estados Nacionais.

Neste caso deve ser ressaltada a aplicação dos direitos fundamentais de terceira dimensão, também considerados como direitos de solidariedade que podem ter sua aplicação estendida a todos os países independentemente da implantação dos mesmos nos ordenamentos jurídicos internos. "A formação das redes internacionais tem como objetivo o de suprir a falta de representatividade real que os parlamentos estão gradualmente perdendo (COSCIONE, 2008, p. 85)

É importante que se remeta a esses direitos de solidariedade quando se pretende dar um enfoque à implantação de um Comércio Justo sujeito às normas transnacionais, pois é impossível entender a existência de tais direitos sem sua inserção em um contexto de uma sociedade eminentemente solidária, cuja preocupação não seja apenas os interesses individuais, mas o coletivo, visando à qualidade de vida e à preservação da espécie humana.

Tal solidariedade é a tônica para o surgimento do Comércio Justo que teria ocorrido de forma incipiente no final do século XIX, quando religiosos com práticas filantrópicas propiciaram uma aproximação de produtores do Sul com consumidores da Europa. Sua 
existência pode ser constatada a partir da década de sessenta como uma reação de determinados organismos internacionais contra as práticas comerciais que estavam sendo utilizadas para aumentar as injustiças e o desequilíbrio sociais.

Tanto aumentava esse desequilíbrio entre os hemisférios Sul e Norte que esse tipo de relação começou a ser questionada pelo fato de o comércio internacional privilegiar somente questões meramente econômicas, tais como diminuição dos custos de transação e aumento de lucros, não importando as consequências desastrosas no âmbito do meio-ambiente, das relações sociais e até mesmo questões macroeconômicas envolvendo Estados soberanos.

A opção do Comércio Justo demonstrava-se politicamente correta e viável à medida que se apresentava como uma alternativa do que se poderia denominar de Estado líbero-social (no qual se entende a existência de um mercado social), cuja ideia seria ao invés de praticar políticas meramente assistenciais, estimular a produção por grupos socialmente desfavoráveis e que não necessitariam de ajudas governamentais. Eis uma faceta a que propõe o Comércio Justo.

O surgimento com os moldes hoje utilizados veio a ser percebido a partir de 1988 na Holanda, com uma característica própria de sistema de certificação que orientava os consumidores na aquisição de produtos oriundos do Comércio Justo. As mercadorias comercializadas nem sempre tinham os melhores preços, pois o custo incluía situações como respeito ao meio-ambiente e a não exploração do trabalho, mas visavam substituir as políticas de assistência por uma rede de solidariedade.

A prática do Comércio Justo, então, proliferou em países europeus e nos Estados Unidos com as formas mais diversas, sendo destaque a utilização do instrumento da certificação. Esse conceito evoluiu rapidamente e em 1997 foi criada a FLO (Fair Trade Labelling Organizations), que passou a ser responsável por emitir um selo de Comércio Justo oriundo de uma sociedade transnacional.

$\mathrm{Na}$ América Latina o pensamento já existia de forma não institucional, findando por ampliar o conceito. O denominado Fair Trade, antes entendido somente para relações comerciais justas entre o Norte e o Sul, incentivava também o comércio Sul-Sul e o comércio interno. Sob tal enfoque, houve um esforço latino para que o Fair Trade não descambasse para uma nova colonização (neo-colonialismo). Desde 2004, a protagonista do Comércio Justo na América Latina é a Coordenadora Latino-americana e do Caribe de Pequenos Produtores e Trabalhadores do Comércio Justo (CLAC). Trata-se de uma rede co-proprietária do Sistema 
Fairtrade International. Embora criada em 2004, a origem da CLAC decorre da Coordenadora Latinoamericana que agrupava os cafeicultores de comércio justo (também denominada CLAC) e dos Pequenos Apicultores da América Latina Unida (PAUAL), duas redes continentais de pequenos produtores, ambas criadas em 1996, um ano antes da criação da FLO (CLAC, 2017).

É necessário que se perceba que o Comércio Justo pressupõe a existência de um tripé representado pela produção, distribuição e consumo, na qual a solidariedade e a sustentabilidade devem servir de bússola para beneficiar produtores em situação de desvantagem, permitindo que se tenha uma melhoria de condições sob vários aspectos, sejam eles econômicos, sociais, políticos, culturais, ambientais e éticos. Em resumo, a iniciativa busca que os produtores pratiquem um preço justo, que os consumidores se contenham em decorrência de um processo educativo e tudo isso resulte no desenvolvimento humano.

\footnotetext{
O comércio justo procura criar os meios e oportunidades para melhorar as condiç̃oes de vida e de trabalho dos produtores, especialmente os pequenos produtores desfavorecidos. A sua missão é de promover a equidade social, a proteção do ambiente e a segurança econômica através do comércio e da promoção de campanhas de conscientização.(FRETEL, 2003, p.65)
}

Não se trata apenas de uma relação comercial, conforme os moldes do comércio comum, objetiva-se ir além dessa proposta. Almeja-se uma experiência que busca uma relação de cooperação e colaboração, nas quais devem ser privilegiados a igualdade e o respeito mútuo. O que se procura alcançar não é baratear os preços em decorrência de relações diretas e solidárias entre o consumidor e o produtor, mas, a construção de um mundo responsável e sustentável.

O comércio justo surge não apenas como uma alternativa de cooperação comercial para os produtores excluídos dos países do Sul, mas como um conjunto de práticas que se inscreve na concepção de trocas que rompe com o paradigma econômico e a visão de desenvolvimento dominante. Neste sentido, possui um poder transformador que possibilita estabelecer outros tipos de relações entre produtores e consumidores, baseadas na equidade, na cooperação, na confiança e em interesses compartilhados. (GOMES, 2016)

A lógica é perceber que o Comércio Justo se configura como uma alternativa a um modelo de relações comerciais que há muito é seguido na civilização ocidental em decorrência da adesão ao capitalismo e todas as suas consequências. Configura-se uma alternativa ao capitalismo decorrente da globalização, pois em seu nascedouro as primeiras 
relações comerciais não tinham a busca pelo lucro como principal objetivo, as negociações diretas entre produtor e consumidor que havia nos primórdios traziam um pouco do conceito de justo de Aristóteles.

Logicamente é necessário que sejam definidas regras jurídicas para que venham a regulamentar este novo estilo de relação comercial, a fim de que se tenha um modelo que se adapte a esse objetivo de se ter proteção ambiental, segurança econômica e principalmente equidade social. O Brasil, seguindo a tendência de preocupação com os movimentos sociais como política governamental da época, adotou procedimentos que promoveriam o Comércio Justo em decorrência de implantação de políticas de estímulo à economia solidária. Sob tal enfoque, Coscione (2008, p. 100) se perguntava: Seremos capazes de entender que certos estilos de vida, certas estruturas institucionais e certas formas de representatividade ao estilo europeu, nem sempre podem ser aplicadas a realidades tão diferentes e sobretudo tão desiguais como as latinos-americanas?

Tanto assim o fez que em novembro de 2010 foi publicado o Decreto $\mathrm{n}^{\circ} 7.358 / 2010$ que instituiu o Sistema Nacional do Comércio Justo e Solidário (SCJS), cujo objetivo segundo o teor do próprio artigo $1^{\circ}$ do citado ato normativo era para coordenar, através do Ministério do Trabalho e Emprego, as ações do Governo Federal voltadas ao reconhecimento de práticas de Comércio Justo e solidário e à sua promoção.

A própria lei trouxe a normatização necessária para a implantação dos meios necessários no Brasil, inclusive com definições visando à orientação e às práticas para a adoção do sistema, conforme o que consta no artigo $2^{\circ}$ :

Art. $2^{\circ}$ Para os efeitos deste Decreto, entende-se por:

I - comércio justo e solidário: prática comercial diferenciada pautada nos valores de justiça social e solidariedade realizada pelos empreendimentos econômicos solidários;

II - empreendimentos econômicos solidários: organizações de caráter associativo que realizam atividades econômicas, cujos participantes sejam trabalhadores do meio urbano ou rural e exerçam democraticamente a gestão das atividades e a alocação dos resultados;

III - organismos de acreditação: organismos que credenciam os organismos de avaliação da conformidade, atestando sua capacidade para realizar tarefas de avaliação da conformidade de produtos, processos e serviços;

IV - organismos de avaliação da conformidade: organismos que inspecionam e atestam o cumprimento dos critérios de conformidade de produtos, processos e serviços com as práticas de comércio justo e solidário; e

V - preço justo: é a definição de valor do produto ou serviço, construída a partir do diálogo, da transparência e da efetiva participação de todos os agentes envolvidos na sua composição que resulte em distribuição equânime do ganho na cadeia produtiva. Parágrafo único. Os termos fair trade, comércio justo, comércio equitativo, comércio équo, comércio alternativo, comércio solidário, comércio ético, comércio 
ético e solidário estão compreendidos no conceito de comércio justo e solidário, nos termos deste Decreto. (BRASIL, 2017)

Embora em vigor, passados seis anos, a adoção do sistema pelo corpo normativo jurídico brasileiro é tímida. Sem dificuldade, é possível perceber que seu êxito poderia colocar em risco e contrariar interesses de empresas há muito tempo instalados no mercado nacional, principalmente na comercialização de alimentos.

Apesar do regramento brasileiro (inédito em seara estatal, mas ineficaz) o fenômeno do Comércio Justo rege-se pela transnacionalização. Afinal, a legislação de um Estado (no caso pátrio, há somente um decreto) pode sofrer alterações e consequentemente fulminar quaisquer interesses de continuidade. $\mathrm{O}$ cenário político atual brasileiro representa esse maniqueísmo.

Excetuando-se o caso pátrio, o Comércio Justo é regido pelos valores da transnacionalização que norteiam seu ordenamento e que vão muito além do maquinismo e da eficiência que regem o free trade.

\begin{abstract}
A realidade do comércio mundial tem colocado em dúvida as fórmulas liberalizantes que motivam o sistema de trocas, pois as construções jurídicas institucionalizadas têm sido incapazes de distribuir riqueza e, principalmente, fomentar a igualdade material entre os Estados. O prometido livre comércio não trouxe a prolatada igualdade de tratamento, fazendo com que os países em desenvolvimento tenham uma árdua missão para desfazer as barreiras, em especial nos grandes mercados. (STELZER, 2016)
\end{abstract}

Por isso, resguardar o Comércio Justo por intermédio de um sistema nacional também é arriscado. Na atualidade, mais seguro é percorrer a ética que demonstra preocupação com a desigualdade social e as questões que afetam as gerações futuras. Tratamse de direitos de solidariedade, notadamente o direito ao desenvolvimento. O eixo axiológico do Comércio Justo não se restringe somente às questões econômicas, abrangendo também direitos civis, políticos, sociais e culturais que propiciem aos indivíduos uma existência digna, tentando alcançar melhorias qualitativas nas condições de vida das pessoas.

Deve ocorrer uma evolução de um contexto caracterizado pela existência de um cidadão de um país rico e desenvolvido em oposição a outro de um país pobre e subdesenvolvido: chegar-se-ia ao cidadão transnacional que busca, por intermédio de ações concretas, o efetivo desenvolvimento. Essa questão do desenvolvimento precisa ter um caráter global, transnacional, para que não se corra risco de aplicação de um crescimento econômico com base no entendimento neoliberal que na realidade redunda em um aumento da 
desigualdade de renda, porque os Estados são obrigados a adotar normas internas que sigam as receitas determinadas pelo Fundo Monetário Internacional (FMI) e pelo Banco Mundial.

Os países subdesenvolvidos foram, portanto, obrigados pelas mencionadas
instituições a tomar uma série de medidas que deveriam garantir o crescimento
econômico, como: privatizar companhias públicas e até serviços tradicionalmente
garantidos pelo poder público; facilitar o livre comércio, renunciando a ou
diminuindo fortemente os impostos sobre as importações e os subsídios à produção
agrícola, industrial ou extrativa nacional (enquanto os países industrializados
seguiam mantendo tais subsídios e impostos); tentar alcançar o equilíbrio no próprio
balanço nacional etc. Tais ações aumentaram a pobreza, como destacam inúmeros
autores, e nem sequer conseguiram produzir o crescimento esperado. Em muitos
casos, houve antes um crescimento zero, 16 podendo-se assim afirmar que as
políticas sugeridas ou até impostas por instituições como o BM e o FMI fracassaram
completamente. As "receitas" contra a pobreza oferecidas pelas organizações
internacionais se revelaram erradas ou inadequadas. (REGO, 2013, p. 169)

Essas receitas mostram-se ineficientes ao serem aplicadas nos limites de determinados Estados, pois se mostram incapazes de salvaguardar tais direitos. Aliás, nem mesmo legislações internacionais têm se mostrado suficientes. Constata-se aqui a significativa superação do Estado nacional com certa permeabilidade para que se resolvam problemas comuns inerentes à humanidade, não sendo possível que se resolvam os problemas globais e difusos de maneira isolada e individual.

Além do mais, a transnacionalidade das normas permitirá que as relações comerciais justas se efetivem sem que haja interferência de órgãos estatais que podem tanto tornar mais caros como criar regulamentos impeditivos para as transações. O que se percebe é que parte da população (notadamente de consumidores) do hemisfério Norte já começa a externar sua preocupação com os cidadãos do mundo sem que haja influência de ideias etnocêntricas. Afinal, as angústias ambientais, de desigualdade de renda, dos conflitos étnicos e religiosos já são compartilhadas sem que existam fronteiras e assim há um movimento para que a solidariedade acabe por gerar sociedades globais preocupadas com questões globais.

Daí o Comércio Justo se mostra como uma das opções adotadas pelo Norte em relação ao Sul (e também do Sul em relação ao Sul), na qual a compra dos produtos é mais que a satisfação de necessidade, é ação política. O comerciante também não se preocupa somente com o lucro, mas também com o retorno social. Estimula-se a produção daqueles que possuem menos e esses acabam tendo condições justas de crescimento econômico. Para o Estado significará menos necessidade de políticas estatais de transferência de renda. Ter-se-á 
então uma transação comercial justa que além de gerar riqueza poderá também contribuir para a redução da desigualdade social com o estímulo a um consumo responsável.

\section{Conclusão}

O Comércio Justo tem seu surgimento determinado como alternativa às transações comerciais comuns que tendem a aumentar a desigualdade entre os países do Norte e os do Sul, pois essas relações decorrentes da globalização permitem que as empresas transnacionais se instalem em países mais pobres com o intuito de diminuir seus custos e aumentar seus lucros. No entanto, é necessário que se estabeleça um critério comum de regulação para as relações de Comércio Justo, evitando a adoção de diferentes formatos legais conforme o Estado que os regule e que poderia resultar em situação que inviabilizasse essas negociações.

Com base nisso, basta que se busque guarida na adoção de direitos de solidariedade que mesmo sendo direitos fundamentais não podem ser inseridos em um contexto de normas constitucionais ou mesmo direitos humanos em virtude de seu caráter difuso, sendo entendido como uma norma que deve ser aplicada indistintamente em outros países, pregando o desenvolvimento, a proteção ao meio-ambiente como necessários para a nossa e as futuras gerações.

A adoção de normas transnacionais viabiliza o Comércio Justo no âmbito mundial, pois além de se pregar um respeito ao meio-ambiente, há também a busca pelo desenvolvimento dos mais pobres, sem que haja necessidade de políticas assistencialistas de transferência de renda. Mais do que isso, haveria um estímulo à produção própria com a garantia da aquisição por parte de consumidores do mundo todo.

O fato de o Brasil possuir regulamentação sobre economia solidária e comércio justo serve muito mais para ratificar a necessidade de um direito transnacional para regular essas relações. Efetivamente, o que se constata é que mesmo havendo regras nacionais, essas não conseguiram difundir esse ideal e, sobretudo, deflagrar um processo de redistribuição de renda com a comercialização de determinados produtos sob a denominação Comércio Justo.

\section{Referências}

ARISTÓTELES. Ética a Nicômaco. Tradução de Leonel Vallandro e Gerd Bornheim. 4.ed. São Paulo: Nova Cultural, 1991. (Os pensadores, v.2)

BECK, Ulrich, O que é Globalização ? Tradução de Andre Carone. São Paulo: Paz e Terra, 1999. 
BRASIL. Dec. 7.358/2010, de 17/11/2010 - Institui o Sistema Nacional de Comércio Justo e Solidário - SCJS, cria sua Comissão Gestora Nacional, e dá outras providencias. Disponível em: <http://www.planalto.gov.br/ccivil_03/_Ato2007-2010/2010/Decreto/D7358.htm> Acesso em: 23/04/17.

BRAUDEL, Fernand. A dinâmica do capitalismo. Tradução de Álvaro Cabral. Rio de Janeiro: Rocco, 1987.

CLAC (Coordenadora Latino-americana e do Caribe de Pequenos Produtores e Trabalhadores do Comércio Justo). O que é o sistema Internacional de Comércio Justo/Fairtrade? Disponível em: <http://clac-comerciojusto.org/pt-br/comercio-justo-pt/sistema-fairtradeinternational/> Acesso em: 03/05/17.

COMPARATO, Fábio Konder. A civilização capitalista: para compreender o mundo em que vivemos. 2.ed. São Paulo: Saraiva, 2014.

COSCIONE, Marco. El Comercio Justo: Una alianza estratégica para el desarrollo de América Latina. Madrid: Los Libros de la Catarata, 2008.

FARIA, José Eduardo. O Direito na Economia Globalizada. São Paulo: Malheiros, 1999.

FRETEL, Alfonso Cotera; SIMONCELLE-BOURQUE, Eloüse. O comércio justo e o consumo ético. Rio de Janeiro: DP\&A; Fase, 2003.

FRIEDEN, Jeffry A. Capitalismo global: História econômica e política do século XX. Tradução de Vivian Mannheimer. Rio de Janeiro: Jorge Zahar Editor, 2008.

GOMES, Rosemary. A Economia Solidária na América Latina e no Caribe. Disponível em: <http://facesdobrasil.org.br/ponto-de-vista/a-economia-solidaria-na-america-latina-e-nocaribe> Acesso em: 31/03/2016.

IANNI, Octavio. A sociedade global. 16.ed. Rio de Janeiro: Civilização Brasileira, 2014.

REGO, Walquiria Leão Vozes do Bolsa Família: autonomia, dinheiro e cidadania. São Paulo: Unesp, 2013.

STELZER, Joana; CRUZ, Paulo Márcio. Direito e Transnacionalidade. Curitiba: Juruá, 2009.

STELZER, Joana; GOMES, Rosemary. Comércio Justo e Solidário na América Latina. Florianópolis: CAD/UFSC, 2016. 